\title{
Atmospheric circulation patterns associated with extreme precipitation amounts in Greece
}

\author{
E. E. Houssos, C. J. Lolis, and A. Bartzokas \\ Laboratory of Meteorology, Department of Physics, University of Ioannina, 45110 Ioannina, Greece \\ Received: 31 December 2007 - Revised: 21 March 2008 - Accepted: 15 May 2008 - Published: 20 June 2008
}

\begin{abstract}
The main synoptic conditions associated with extreme precipitation amounts in Greece are examined by using a multivariate statistical methodology comprising S-mode Factor Analysis and k-means Cluster Analysis. The following data were used : i) daily precipitation amounts (measured at 06:00 UTC) for the meteorological stations of Hellenikon (Athens), Thessaloniki (northern Greece) and Ioannina (western Greece) and ii) daily (18:00 UTC) $2.5 \times 2.5$ grid point values of $500 \mathrm{hPa}$ geopotential height, mean sealevel pressure and $1000-500 \mathrm{hPa}$ thickness at 273 grid points over Europe ( $10 \mathrm{~W}$ to $40 \mathrm{E}$ and $30 \mathrm{~N}$ to $60 \mathrm{~N}$ ), for the period 1970-2002.
\end{abstract}

The dates corresponding to the upper $5 \%$ of the frequency distribution of precipitation are selected for each one of the three stations. In total, 369 dates are used, some of them being common among the three stations. The corresponding $369 \times 273$ data matrices of $500 \mathrm{hPa}$ geopotential height, mean sea-level pressure and 1000-500 hPa thickness are constructed. The rows refer to the 369 extreme precipitation cases and the columns refer to the 273 grid points. The three matrices are unified into one $369 \times 819$ matrix. In order to reduce the dimensionality of the data set, S-mode Factor Analysis is applied to the unified matrix, revealing 7 factors accounting for $85 \%$ of the total variance. Finally, k-means Cluster Analysis is applied to the factor scores matrix, classifying the 369 cases into 9 clusters.

For each one of the 9 clusters, the mean 18:00 UTC patterns of the above parameters are constructed and presented. These patterns correspond to the main distinct atmospheric circulation structures favoring extreme precipitation amounts in Greece. Most of the patterns are characterized by enhanced cyclonic activity over or near the Greek area. The differences among the 9 circulation structures refer mainly to the position and the intensity of the surface and the upper air synoptic systems involved. Some of the 9 synoptic con-

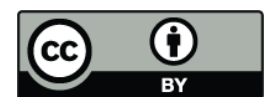

Correspondence to: A. Bartzokas (abartzok@uoi.gr) ditions favor extreme precipitation amounts mainly at one or two of the three stations while some others equally affect the three stations.

\section{Introduction}

Over the past few years, extensive research has been carried out on extreme precipitation events (see e.g. Gellens, 2000; Kunkel, 2003; Xoplaki et al., 2004; Cislaghi et al., 2005; Houssos et al., 2006). Research studies involving trends, extremes and variations of the precipitation regime over Europe and the Mediterranean are of great significance, as precipitation may cause serious problems for the everyday human activities (e.g. transportations and communications) and may be responsible for severe damages in urban as well as in rural areas. Extreme precipitation events have been studied by using several different methodologies. For example, the numerical modeling and statistical analysis are two main approaches that have been widely used (see e.g. Metaxas et al.,1993; Romero et al., 1998; Jansa et al., 2000, 2001; Kutiel et al., 2001; Kostopoulou and Jones, 2005; Tolika and Maheras, 2005). In the present study, the extreme precipitation amounts measured at three meteorological stations in Greece and their relation with atmospheric circulation are examined, by using a multivariate statistical methodology scheme, including Factor Analysis and Cluster Analysis.

\section{Data and methodology}

Daily precipitation amounts, measured at 06:00 UTC, at the meteorological stations of Hellenikon (Athens), Thessaloniki (northern Greece) and Ioannina (western Greece) and daily (18:00 UTC) $2.5 \times 2.5$ grid point values of $500 \mathrm{hPa}$ geopotential height, mean sea-level pressure and 1000-500 hPa thickness at 273 grid points over Europe and the Mediterranean region $(10 \mathrm{~W}$ to $40 \mathrm{E}$ and $30 \mathrm{~N}$ to $60 \mathrm{~N})$, were analyzed for the period 1970-2002. The precipitation data set was provided by the Hellenic National Meteorological Service and

Published by Copernicus Publications on behalf of the European Geosciences Union. 
Table 1. The number of extreme precipitation cases and the corresponding thresholds.

\begin{tabular}{llll}
\hline Station & Cases & $\mathbf{5 \%}$ Threshold (mm) & Percentage \\
\hline Thessaloniki & 110 & 20.0 & $29.8 \%$ \\
Athens & 84 & 24.7 & $22.7 \%$ \\
Ioannina & 151 & 34.2 & $40.9 \%$ \\
Ath.-Ioan. & 2 & & $0.6 \%$ \\
Thes.-Ath. & 9 & & $2.4 \%$ \\
Thes.-Ioan. & 11 & & $3.0 \%$ \\
Thes.-Ath.-Ioan. & 2 & & $0.6 \%$ \\
Total & 369 & & $100.0 \%$ \\
\hline
\end{tabular}

the University of Ioannina meteorological station archives and the grid point data set was derived from the ECMWF ERA40 Reanalysis Project.

For each meteorological station, the upper $5 \%$ of the distribution of all the daily precipitation amounts is selected and the corresponding 24-h periods are characterized as extreme precipitation cases (EPCs). In Table 1, the number of cases and the corresponding 5\% precipitation thresholds for each station are shown. There are 369 extreme precipitation cases that refer to at least one of the three meteorological stations. Note that only 24 cases (7\%) are common to two or even three stations.

For these 369 cases, three matrices of 369 rows by 273 columns are constructed from the grid point dataset. The columns of the three matrices correspond to the $500 \mathrm{hPa}$ geopotential height, mean sea-level pressure and 1000500 hpa thickness values, respectively, at the 273 grid points, at 18:00 UTC of the day before the precipitation measurement. The time 18:00 UTC is selected as it is the middle of the 24-h period to which the precipitation measurement refers to. Then, the three matrices are unified into one matrix of 369 rows by 819 columns. The rows of the new matrix correspond to the 3-dimensional structures of the atmosphere over Europe and the Mediterranean, associated with extreme precipitation amounts over Greece. In order to reduce the dimensions of the dataset, Factor Analysis (Jolliffe, 1986; Manly, 1986) is applied to the unified matrix and 7 factors are revealed accounting for at least $85 \%$ of the total variance of the initial variables. In this work, Factor Analysis is used as an intermediate tool for data reduction only and therefore its results are not presented. Next, K-Means Cluster Analysis is applied to the factor scores matrix (369 rows $\mathrm{x} 7$ columns) in order to classify the 369 cases into homogeneous distinct clusters that correspond to the main atmospheric circulation structures associated with extreme precipitation amounts over Greece. A similar methodology has been used in other previous studies (Plaut and Simonnet, 2001; Houssos et al., 2007; Lana et al., 2007). The number of clusters is decided by taking into account the results of a procedure called "jump method", which is based on distortion, a

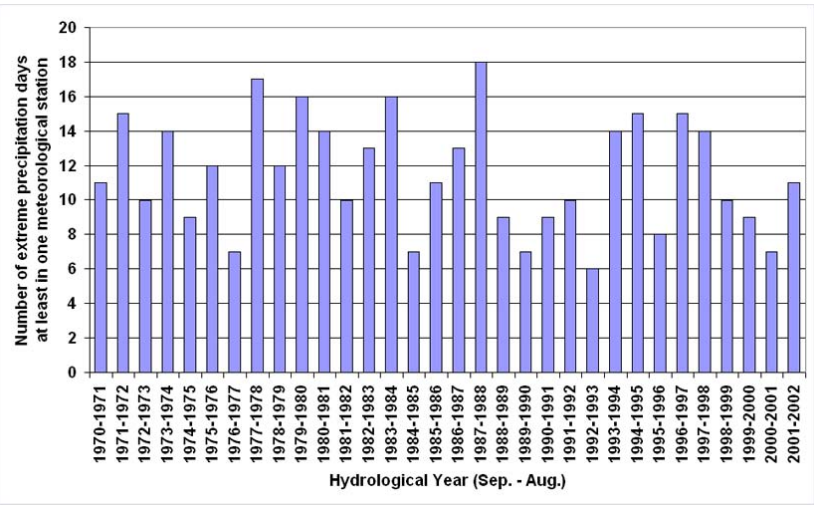

Fig. 1. Time series of the number of extreme precipitation cases per hydrological year (September-August).

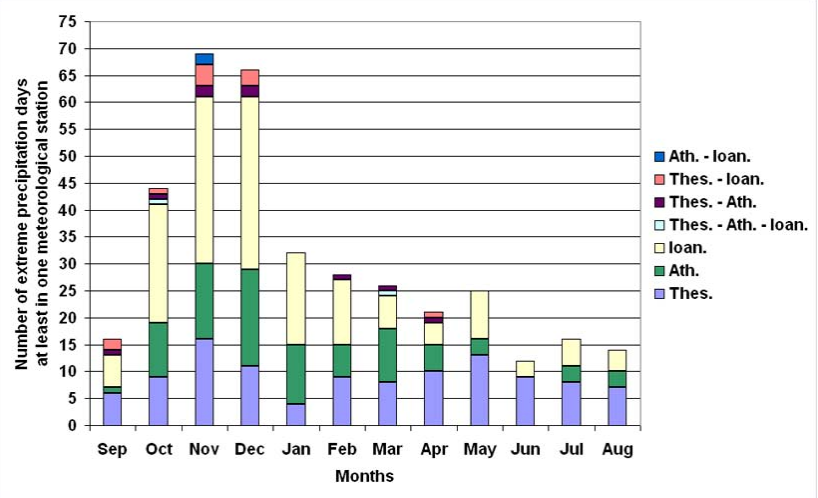

Fig. 2. Intra-annual variability of the number of extreme precipitation cases.

measure of within-cluster dispersion, proposed by Sugar and James (2003). The application of K-Means Cluster Analysis leads to 9 clusters and for each one of the 9 clusters the mean patterns of $500 \mathrm{hPa}$ geopotential height, $1000-500 \mathrm{hPa}$ thickness and mean sea level pressure are constructed and presented in Sect. 3.2.

\section{Results}

\subsection{General characteristics}

In Fig. 1, the time series of the extreme precipitation cases is shown for the period 1970-2002. No statistically significant (95\% confidence level) positive or negative trend is found. However, it can be mentioned that the number of extreme precipitation cases is relatively low around 1990, in relation to the high NAO index during this period.

The intra-annual variability (Fig. 2) shows that, in general, November and December are the months characterized by the highest frequency of extreme precipitation cases in Greece. Specifically, for Thessaloniki (Northern Greece) the 

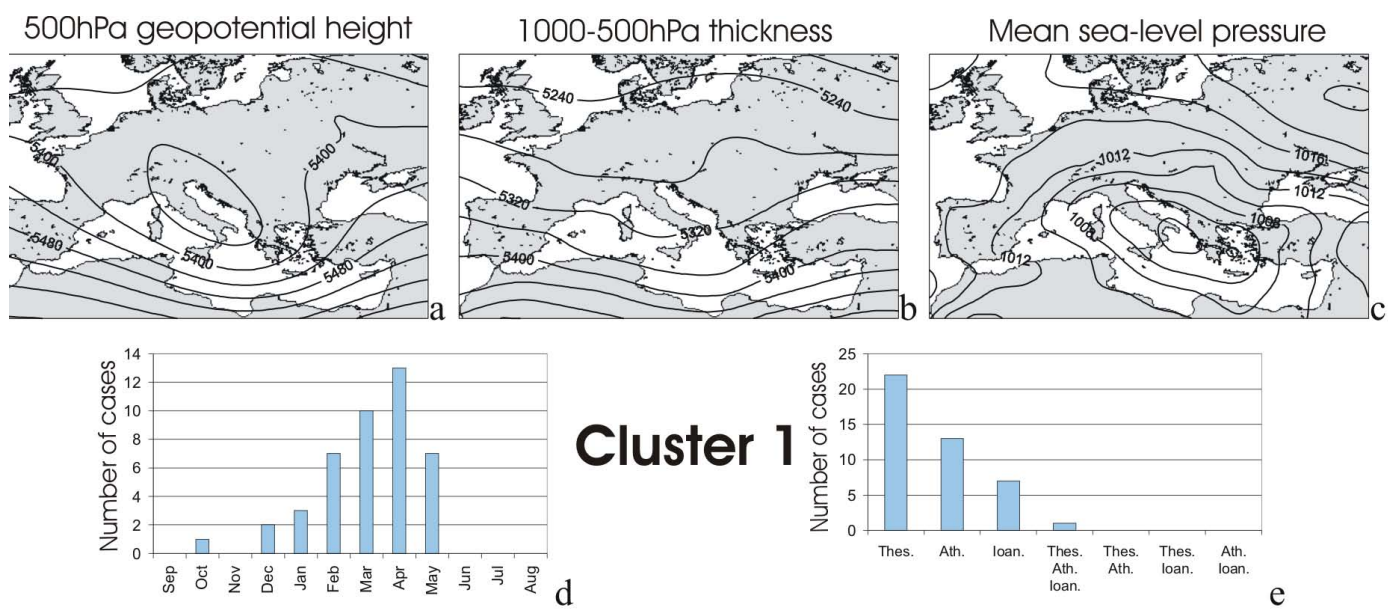

Fig. 3. Mean patterns of: (a) $500 \mathrm{hPa}$ geopotential height, (b) $1000-500 \mathrm{hPa}$ thickness and (c) mean sea-level pressure, for cluster 1 . Also: (d) the intra-annual variation of the number of extreme precipitation cases and e) the number of extreme precipitation cases in each meteorological station.
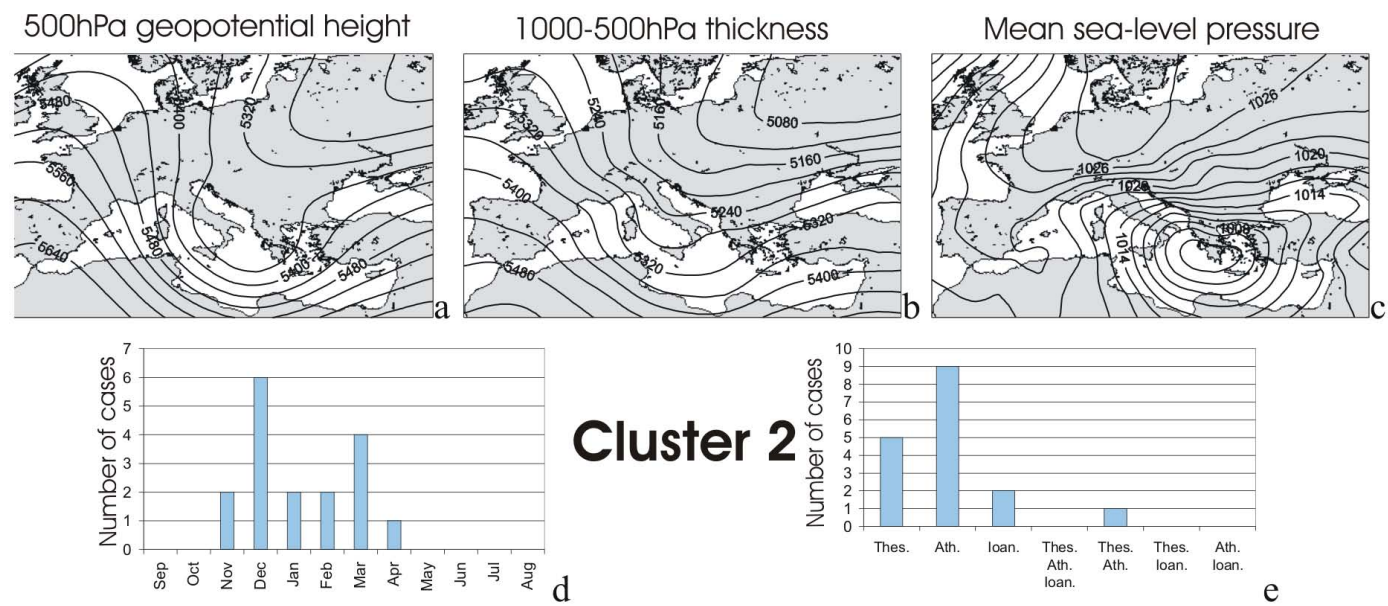

Fig. 4. As for Fig. 3, but for cluster 2 .
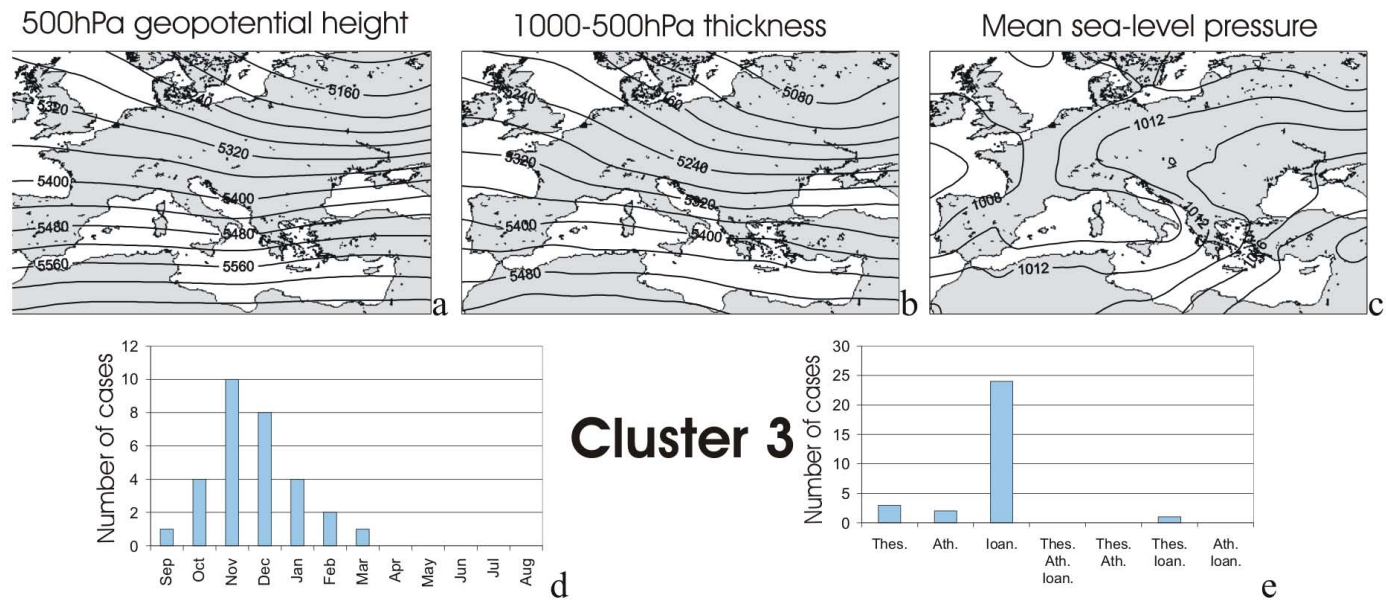

Fig. 5. As for Fig. 3, but for cluster 3. 

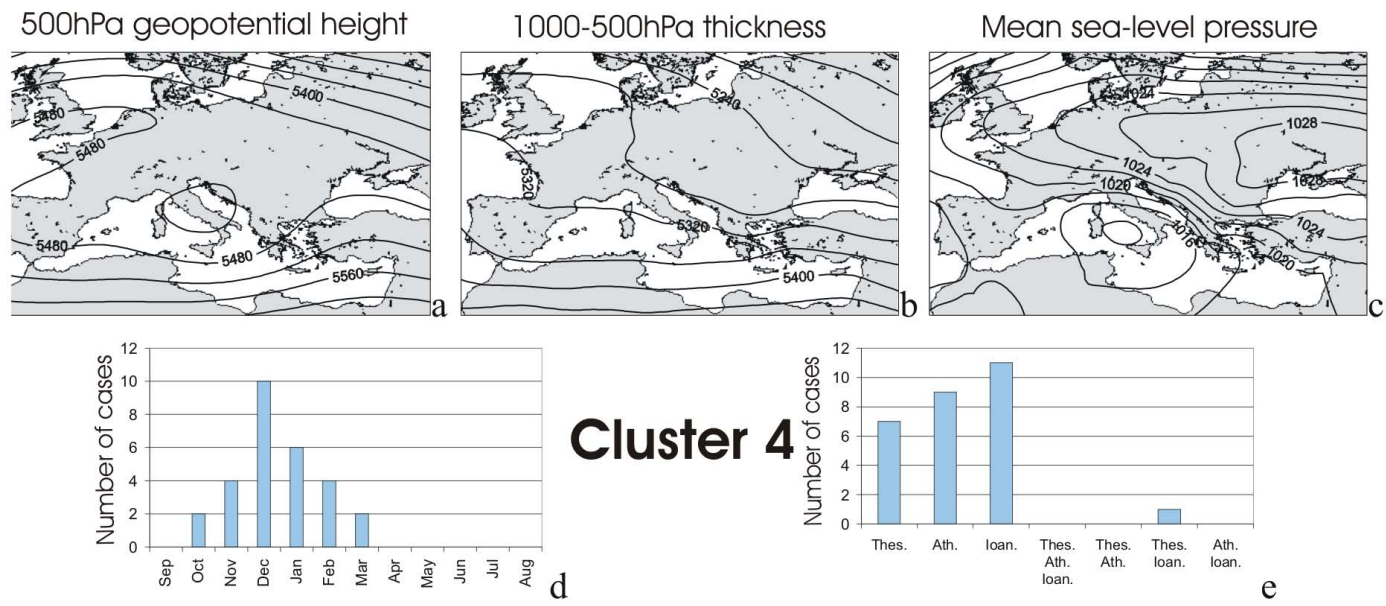

Fig. 6. As for Fig. 3, but for cluster 4.
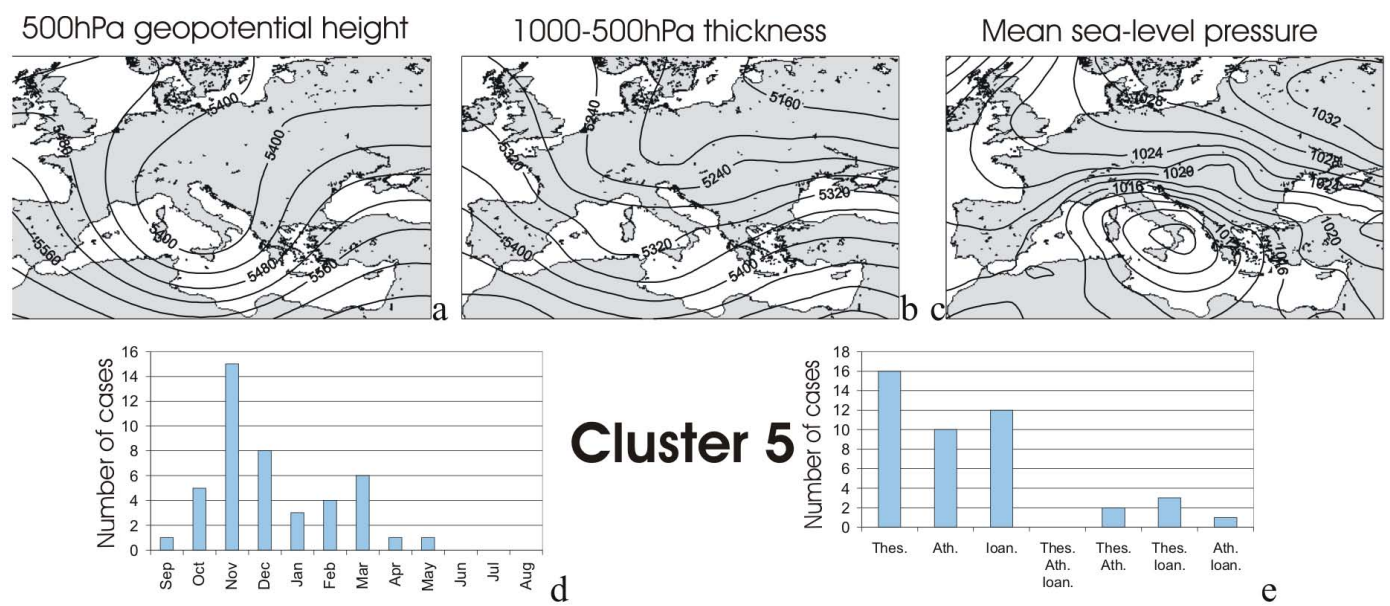

Fig. 7. As for Fig. 3, but for cluster 5.
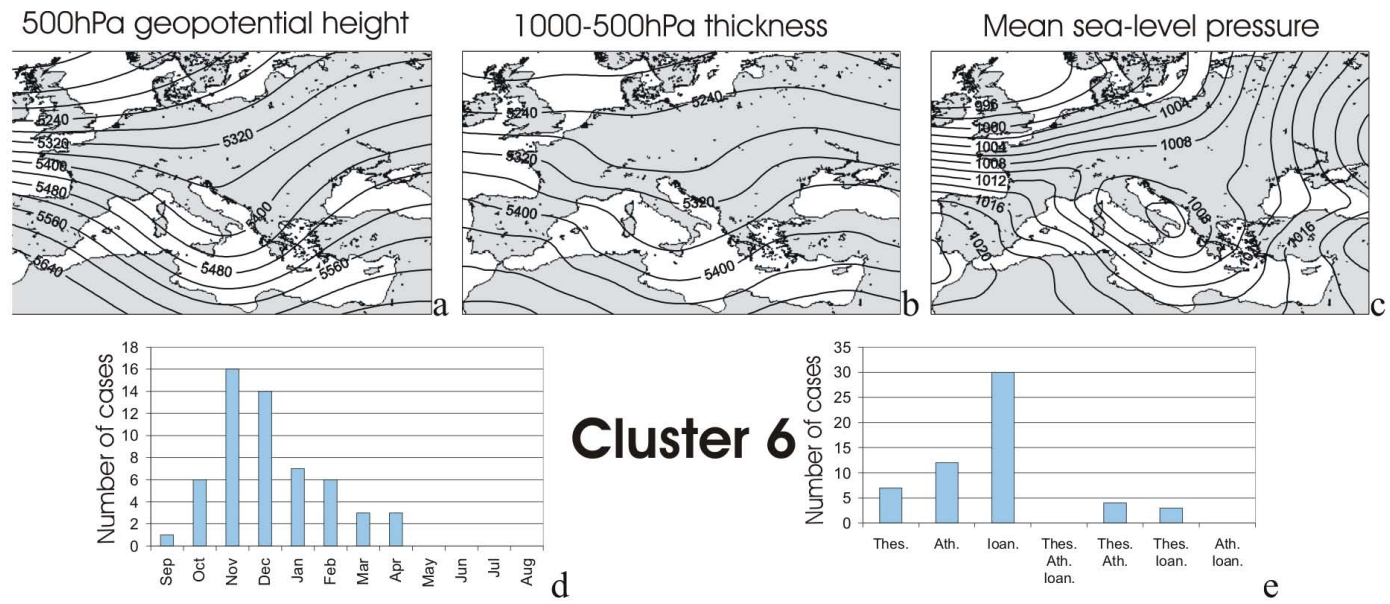

Fig. 8. As for Fig. 3, but for cluster 6 . 

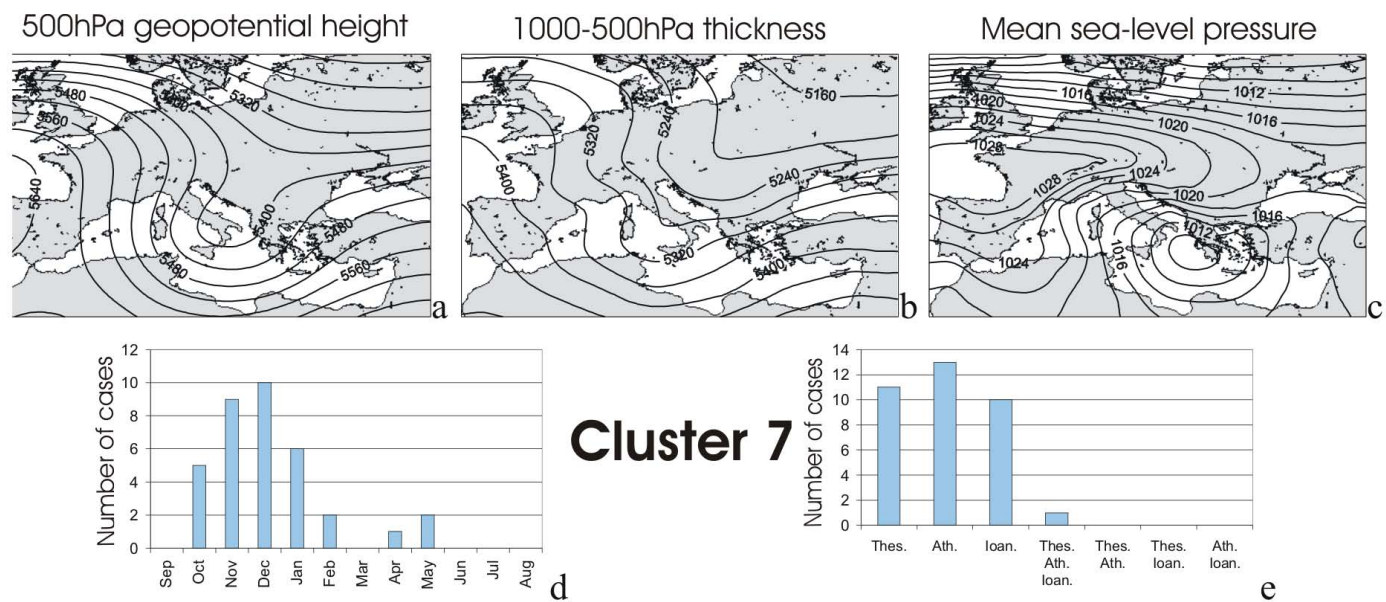

Fig. 9. As for Fig. 3, but for cluster 7.
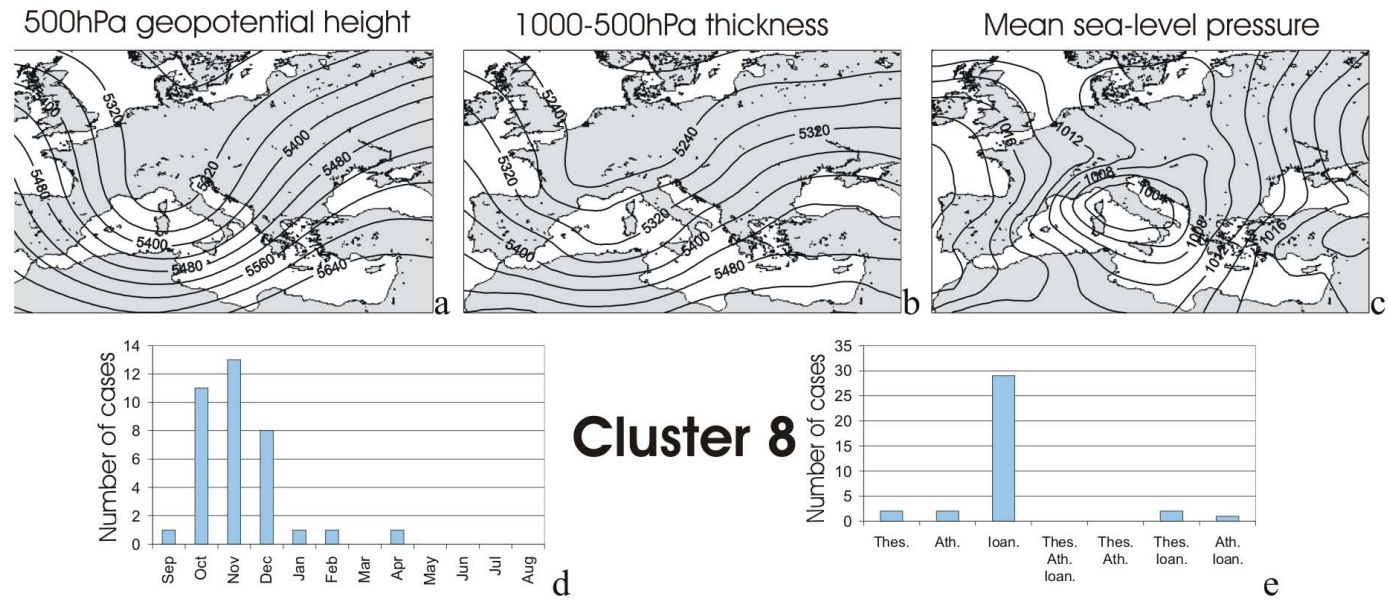

Fig. 10. As for Fig. 3, but for cluster 8 .
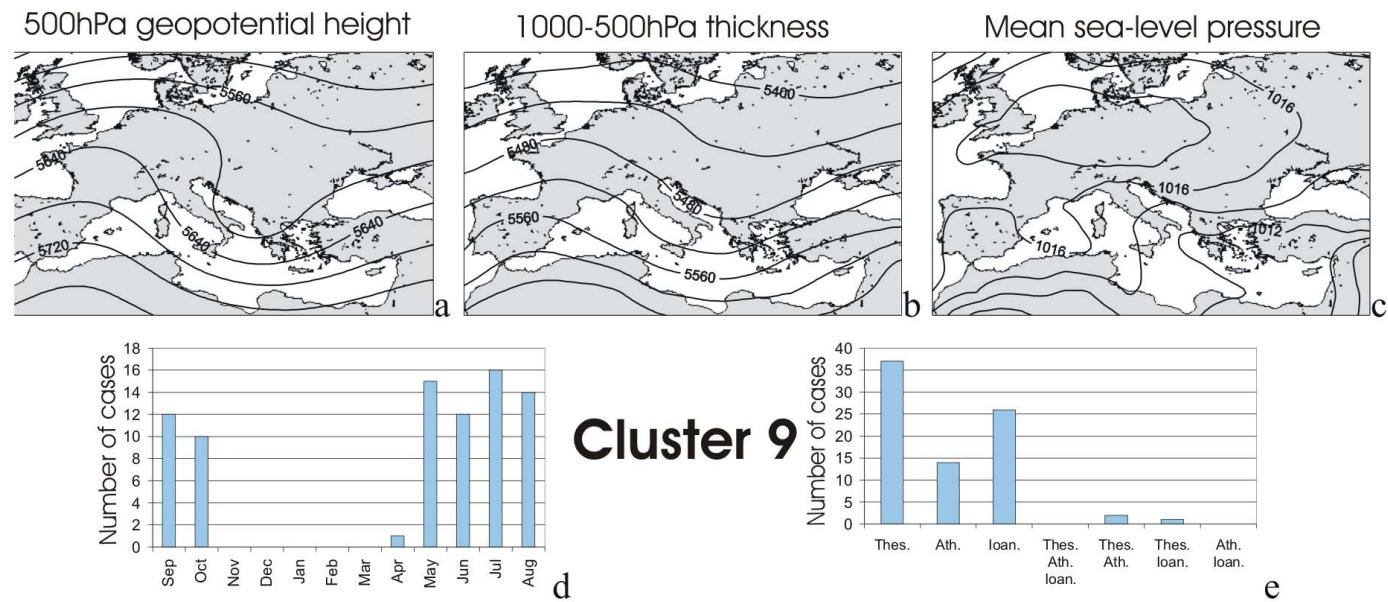

Fig. 11. As for Fig. 3, but for cluster 9. 
primary maximum of EPCs number is recorded in November and the secondary one in May. For Ioannina (Western Greece), EPCs are expected mainly during late autumn and early winter, while May is a month that is also characterized by high frequency of EPCs. For Athens (Central Greece), the months presenting the highest frequency of EPCs are November and December too, but the secondary maximum is reported in March. EPCs in at least two stations simultaneously are expected to happen mainly in autumn and early winter, while such a case has never been recorded during summer.

\section{Classification}

For each one of the 9 clusters the mean patterns of $500 \mathrm{hPa}$ geopotential height, $1000-500 \mathrm{hPa}$ thickness and mean sea level pressure are constructed and shown in Figs. 3 to 11. Note that the 9 Clusters present the three-dimensional structure of the atmosphere (lower troposphere, middle troposphere, temperature distribution) during the extreme precipitation events and thus each one of them has to be studied as the whole set of the 3 weather maps. A brief description of the findings of this work is given below:

Cluster 1 (43 cases): In the middle troposphere $(500 \mathrm{hPa})$ a low pressure system is well established over Italy and the corresponding surface depression is centered over the Ionian Sea (Fig. 3) causing a south-easterly flow over Greece and extreme precipitation amounts mainly in Thessaloniki, especially during spring.

Cluster 2 (17 cases): In the middle troposphere, an upper trough is shown over Greece, while in the lower troposphere, a deep depression is centered over the Peloponnesus peninsula (Fig. 4). The easterly humid flow over central and northern Greece is associated with extreme precipitation amounts in Athens and Thessaloniki. Ioannina (west Greece) is less affected by this system, as it is located in the leeward side of the Pindus mountain range where the easterly flow is dry catabatic. These synoptic conditions prevail mainly in early winter and in early spring.

Cluster 3 (30 cases): In the middle troposphere, a westerly flow prevails over the whole Mediterranean region, while in the lower troposphere cyclonic activity prevails over the west Mediterranean (Fig. 5). The associated southerly surface flow over Greece is responsible for the incidence of EPCs mostly in the western windward areas in late autumn and early winter.

Cluster 4 (28 cases): A depression over the Tyrrhenian Sea combined with a surface anticyclone over eastern Europe causes a south-easterly flow over Greece, affecting the three stations evenly (Fig. 6).

Cluster 5 (44 cases): A deep vertically extended depression over Italy causes synoptic conditions over Greece similar to those of cluster 4. EPCs of this cluster seem to be more frequent in late autumn and early spring, and many of them refer to at least two stations (Fig. 7).

Cluster 6 (56 cases): An upper air trough is located over Italy (Fig. 8). The corresponding surface low-pressure system over the Adriatic Sea causes a southerly humid flow over west Greece affecting mainly Ioannina during early winter. This is in accordance with the findings of Bartzokas et al. (2003).

Cluster 7 (35 cases): An upper air trough with NE-SW orientation and a deep surface depression in the area south-west of Greece are responsible for rainy conditions in most areas of Greece. It is worth mentioning, that the only case with extreme precipitation in all the three stations simultaneously belongs to this cluster. This atmospheric circulation pattern is most common during winter (Fig. 9).

Cluster 8 (36 cases): A large-scale upper air trough over central Europe and a surface depression over Italy is a circulation structure mainly occurring in autumn, affecting western Greece, as it can be seen in Fig. 10.

Cluster 9 (80 cases): This can be characterized as a typical summer circulation structure (Fig. 11). An upper air trough associated with the presence of cold air masses over the Balkans is responsible for high instability conditions over Greece. The high instability along with the strong land heating during summer leads to extreme precipitation mainly in Thessaloniki and Ioannina.

\section{Conclusions}

The synoptic conditions of 369 cases of extreme precipitation amounts are objectively grouped into 9 homogeneous and distinct clusters. The main common characteristic among the 9 clusters is the cyclonic activity over the central Mediterranean. The main differences among them are: i) the exact position and the intensity of the surface and the upper air systems, ii) the season of their prevalence and iii) the exact direction of the surface air flow, being strongly connected to the spatial distribution of extreme precipitation in the Greek area.

Acknowledgements. The present study has been supported by the PENED Programme 2003 for the support of research potential (Ministry of Development/GSRT- 3rd EU Framework Programme/Operational Programme of Competitiveness).

Edited by: A. Mugnai

Reviewed by: one anonymous referee

\section{References}

Bartzokas, A., Lolis, C. J., and Metaxas, D. A.: The $850 \mathrm{hPa}$ relative vorticity centres of action for winter precipitation in the Greek area, Int. J. Climatol., 23, 813-828, 2003.

Cislaghi, M., De Michele, C., Ghezzi, A., and Rosso R.: Statistical assessment of trends and oscillations in rainfall dynamics: 
Analysis of long daily Italian series, Atmos. Res., 77, 188-202, 2005.

Gellens, D.: Trend and Correlation Analysis of k-Day Extreme Precipitation over Belgium, Theor. Appl. Climatol., 66, 117-129, 2000.

Houssos, E. E. and Bartzokas, A.: Extreme precipitation events in NW Greece, Adv. Geosci., 7, 91-96, (http://www.copernicus. org/EGU/adgeo/7/adgeo-7-91.pdf), 2006.

Houssos, E. E., Lolis, C. J., and Bartzokas, A.: The atmospheric conditions over Europe and the Mediterranean, favoring snow events in Athens, Greece, Adv. Geosci., 12, 127-135, (http: //www.adv-geosci.net/12/), 2007.

Jansa, A., Genoves, A., and Garcia-Moya, J. A.: Western Mediterranean cyclones and heavy rain. Part I: Numerical experiment concerning the Piedmont flood case, Meteorol. Appl., 7, 323333, 2000.

Jansa, A., Genoves, A., Picornell, M. A., Campins, J., Riosalido, R., and Carretero, O.: Western Mediterranean cyclones and heavy rain. Part 2: Statistical approach, Meteorol. Appl., 8, 43-56, 2001.

Jolliffe, I. T.: Principal Component Analysis, Springer, New York, 271 pp., 1986.

Kostopoulou, E. and Jones, P. D.: Assessment of climate extremes in the Eastern Mediterranean, Meteorol. Atmos. Phys., 89, 6985, 2005.

Kunkel, K. E.: North American Trends in Extreme Precipitation, Nat. Hazards, 29, 291-305, 2003.
Kutiel, H., Hirsch-Eshkol, T. R., and Turkes, M.: Sea level pressure patterns associated with dry or wet monthly rainfall conditions in Turkey, Theor. Appl. Climatol., 69, 39-67, 2001.

Lana, A., Campins, J.,Genoves, A., and Jansa, A.: Atmospheric patterns for heavy rain events in the Balearic Islands, Adv. Geosci., 12, 27-32, (http://www.adv-geosci.net/12/27/2007/), 2007.

Manly, B. F. J.: Multivariate statistical methods: A primer, Chapman \& Hall, London, 159 pp., 1986.

Metaxas, D. A., Bartzokas, A., Repapis, C. C., and Dalezios, N. R.: Atmospheric circulation anomalies in dry and wet winters in Greece, Meteorol. Z., 2, 127-131, 1993.

Plaut, G., and Simonnet, E.: Large-scale circulation classification, weather regimes, and local climate over France, the Alps and Western Europe, Climate Res., 17, 303-324, 2001.

Romero, R., Guijarro, J. A., Ramis, C., and Alonso, S.: A 30-year (1964-1993) daily rainfall data base for the Spanish Mediterranean regions: first exploratory study, Int. J. Climatol., 18, 541560, 1998.

Sugar, A. C. and James, M. G.: Finding the Number of Clusters in a Dataset: An Information-Theoretic Approach, J. Am. Stat. Assoc., 98, 750-763, 2003.

Tolika, K. and Maheras, P.: Spatial and temporal characteristics of wet spells in Greece, Theor. Appl. Climatol., 81, 71-85, 2005.

Xoplaki, E., Gonzalez-Rouco, J. F., Luterbacher, J., and Wanner, H.: Wet season Mediterranean precipitation variability: influence of large dynamics and trends, Clim. Dynam., 23, 63-78, 2004. 